\title{
Affordable and environmentally friendly method for the synthesis of a green silver nanophotocatalyst based on Mespilus germanica
}

\author{
Mahnoosh Rashidi ${ }^{1}$. Mohammad Reza Islami ${ }^{1}$. Daryoush Tahmassebi ${ }^{2}$ (I)
}

Received: 29 November 2019 / Accepted: 10 March 2020 / Published online: 16 March 2020

(c) Springer Nature Switzerland AG 2020

\begin{abstract}
Leaves of Mespilus germanica have been utilized as a green and inexpensive reducing and stabilizing agent to synthesize silver nanoparticles without using any capping agent or harsh and toxic solvents. In this protocol a silver nanophotocatalyst was synthesized by a green method via immobilization of Ag NPs on the surface of Mespilus germanica seed as a green photocatalyst. The biosynthesized nanophotocatalyst was characterized by ultraviolet-visible, Fourier-transform infrared, $X$-ray diffraction, field emission scanning electron microscopy, energy dispersive $X$-ray spectroscopy, and transmission electron microscopy. The photocatalytic activity of the synthesized silver nanocatalyst was investigated by using it for the degradation of methylene blue under sunlight. The results showed good photocatalytic activity without any agglomeration. In addition, the silver nanophotocatalyst can be recycled and reused several times in the same reaction without significant loss of activity.
\end{abstract}

\section{Graphic abstract}
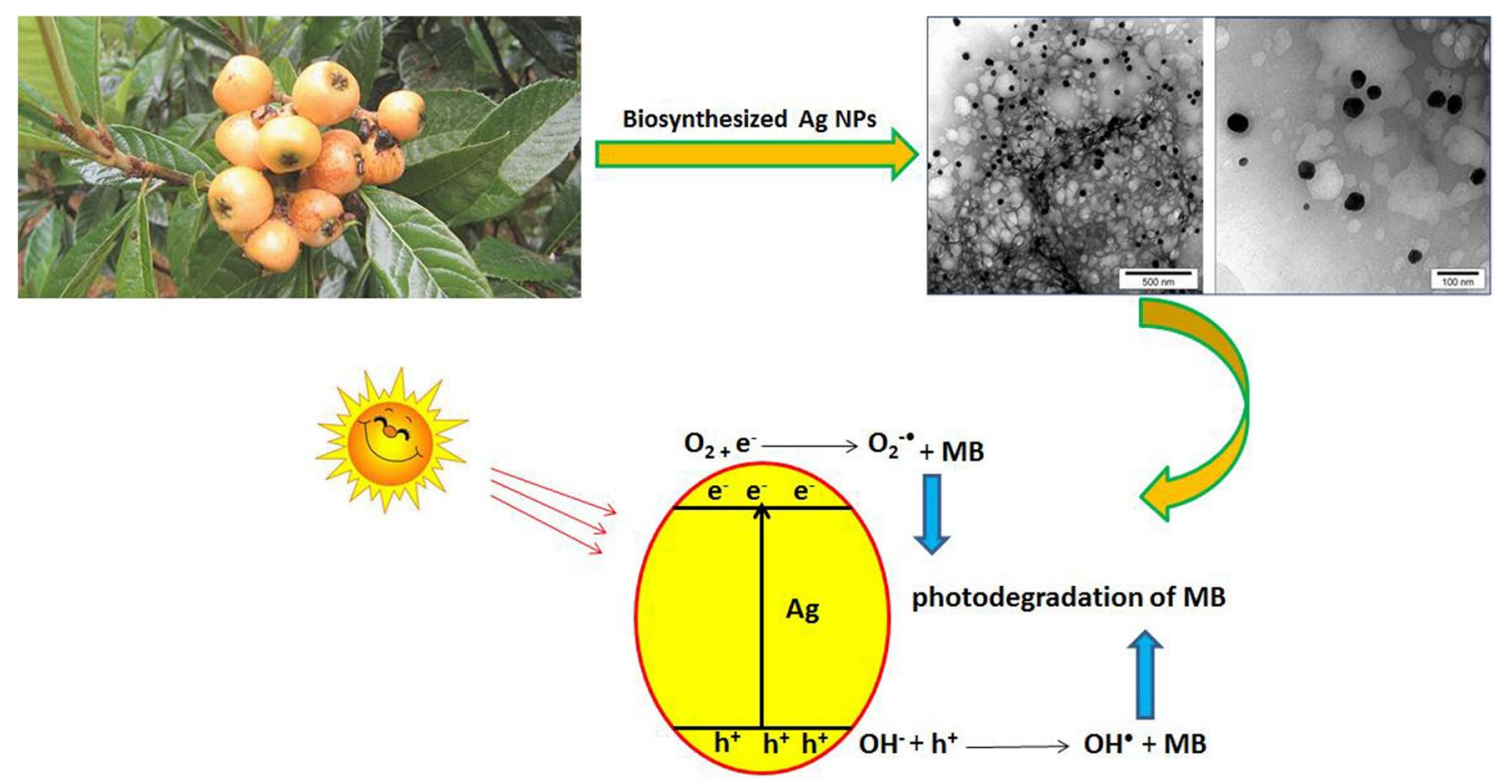

photodegradation of $\mathrm{MB}$

Mohammad Reza Islami, mrislami@uk.ac.ir; $\square$ Daryoush Tahmassebi, tahmassd@pfw.edu| ${ }^{1}$ Chemistry Department, Shahid Bahonar University of Kerman, Kerman 76169, Iran. ${ }^{2}$ Department of Chemistry, Purdue University Fort Wayne, Fort Wayne, IN, USA. 
Keywords Nanophotocatalyst · Mespilus germanica seed · Green synthesis · Ag NPs · Photodegradation · Methylene blue

\section{Introduction}

Pollution is currently one of the biggest concerns of societies. It has a real effect not only on environment but also on people's lives [1]. There have been many efforts to eliminate or at least minimize the environmental impact of chemical processes and use of photocatalysts is one of the cleanest and cost-effective methods [2]. A photocatalyst could be activated in an aqueous solution and in the presence of sunlight and is normally not very sensitive to temperature [3-7].

Metal nanoparticles have been used widely in chemistry as well as in optics and electronics. They can be tuned to photo-degradation of organic dyes [8-13]. The reduced size of metal nanoparticles results in a high surface to volume ratio which can enhance the reactant-catalyst interaction [14-16]. Silver nanoparticles (Ag NPs) are capable of absorbing visible light through electronic transitions between the bands and are prominent as active photocatalysts in the sunlight frequency range [17-19]. They have high optical and thermal performance due to their surface plasmon resonance properties [20]. There are many reports in the literature on the application of Ag NPs as a photocatalyst [21-25] and they have been widely used in different industries because of their low toxicity and antibacterial properties [26, 27]. Ag NPs have been used extensively in electronic industries to enhance electrical conductivity [28] or for printable electronics [29]. However, using Ag NPs as a photocatalyst in the pure form is limited because of agglomeration and recombination of electron-hole pairs. These issues can be resolved by using substrates with good dispersion ability to stabilize and immobilize nanoparticles [30].

Applications of green methodologies for the preparation of silver nanoparticles have more merit than conventional physical and chemical methods. One of the methods of this approach is use of plant extracts as a natural and inexpensive resource for the synthesis of various nanoparticles with suitable shapes and sizes [31-37]. These extracts play an important role in the stabilizing, reducing, and capping of nanoparticles [38-45]. Therefore, attempts to synthesize these nanoparticles with green technology and using plant extracts are becoming more popular.

Mespilus germanica belongs to the Rosaceae flower family [46] and grows in various weather conditions and in many locations such as North Anatolia, Southeastern Europe and Iran [47]. Different parts of this plant such as its fruit, flower and leaves have been widely used in traditional medicine to treat diarrhea, bloating and gastric acid, intestinal swelling, and oral ulcers $[48,49]$. The Mespilus germanica fruit seed contains ascorbic acid (AA) and a high total phenolic content which is responsible for its antioxidant activity [46]. These functional groups could be used as active sites to immobilize silver nanoparticles (Ag NPs). Overall, leaf extract of Mespilus germanica could be considered a natural source of antioxidants, phenolic acids, flavonoids, fatty acids and tannins [50,51].

In continuation of our work on the green preparation of nanomaterials \{Rashidi, $2019 \# 50\}$, herein we report the use of Mespilus germanica leaf extract for biosynthesis of Ag NPs. The Mespilus germanica leaf extract was used as a reducing and capping agent to synthesis Ag NPs without using any toxic and additive substances. Ag NPs were immobilized on the Mespilus germanica seed as a green and inexpensive support for the preparation of nanophotocatalysts. The synthesized nanophotocatalyst was used for photodegradation of methylene blue under sunlight. The obtained results showed that the synthesized nanophotocatalyst has a high photocatalytic activity, and can be recycled and reused without significant decrease in its activity.

\section{Experimental}

\subsection{Instruments and reagents}

Silver nitrates $\left(\mathrm{AgNO}_{3}\right)$, methylene blue $(\mathrm{MB})$ and solvents were purchased from Merck and Aldrich chemical companies and used without further purification, Mespilus germanica was obtained from Shiraz area, (City of Shiraz, Province of Fars, Iran). Products were identified by comparing their physical and spectral data with those of known compounds. The synthesized nanophotocatalyst was characterized by Infrared Spectroscopy (FT-IR Bruker, Germany, RT-DLATGS detector). The X-ray Diffraction (XRD) patterns were examined on a model X'PertPro diffractometer (Panalytical, Almelo, and the Netherlands) using $\mathrm{Cu}$ Ka radiation. Ultraviolet-visible Spectroscopy (UV-Vis) was performed in the range of $200-900 \mathrm{~nm}$ on a Cary 50 single detector double beam in time spectrophotometer (Varian, Australia). The morphologies and sizes of the prepared samples were characterized by A LEO 912AB Transmission Electron Microscopy [49] with an accelerating voltage of $100 \mathrm{kV}$, Free Emission Scanning Electron Microscopy (FESEM-TESCAN-MIRA3) and Energy Dispersive X-ray Spectroscopy (EDX, FESEM-TESCAN MIRA3). 


\subsection{Preparation of Mespilus germanica leaf extract (MGLE)}

The leaves of Mespilus germanica were washed with distilled water, and then completely dried and powdered. The phytocompounds were extracted using a Soxhlet extractor. The extract solution has been prepared by adding deionized water $(175 \mathrm{~mL})$ and ethanol $(175 \mathrm{~mL})$ into a $500 \mathrm{~mL}$ flask and the dried Mespilus germanica leaf powder $(10 \mathrm{~g})$ was placed in Soxhlet cartridge. The solution was heated to $100^{\circ} \mathrm{C}$ for $24 \mathrm{~h}$ and then solvents were removed using a rotary evaporator. The extract was dried at room temperature and stored in a refrigerator.

\subsection{Biosynthesis of Ag NPs using MGLE}

$2 \mathrm{~mL}$ of MGLE ( $3.5 \% \mathrm{w} / \mathrm{v}$ ) was stirred into an aqueous solution of $\mathrm{AgNO}_{3}\left(10 \mathrm{mg} \mathrm{AgNO}\right.$ in $10 \mathrm{~mL}$ water) at $60^{\circ} \mathrm{C}$. The biosynthesized Ag NPs completely formed in about $10 \mathrm{~min}$ by reduction of the silver ions $\left(\mathrm{Ag}^{+}\right)$to $\mathrm{Ag}$ NPs and the color of the solution gradually changed from brown to dark indicating the formation of the Ag NPs. The resulting solution was analyzed by UV-Vis spectrophotometry. The precipitated Ag NPs was centrifuged at $3500 \mathrm{rpm}$ for $15 \mathrm{~min}$. The precipitate was subsequently washed with water and ethanol to remove uncoordinated phytochemicals and the black powder silver nanoparticle was dried overnight at room temperature.

\subsection{Green synthesis of Ag NPs/Mespilus germanica seed nanophotocatalyst (Ag NPs/MGS NPC)}

The silver photonanocatalyst has been prepared according to our recently reported method [51]. The Mespilus germanica seeds were washed with distilled water, dried, formed into a powder and dried overnight at room temperature. In order to prepare the Ag NPs/Mespilus germanica seed, $0.1 \mathrm{~g}$ of Mespilus germanica seed powder was mixed in water and then aqueous solution of $\mathrm{AgNO}_{3}$ (10 $\mathrm{mg} \mathrm{AgNO}_{3}$ in $10 \mathrm{~mL}$ water) was added to the mixture and stirred at $60^{\circ} \mathrm{C}$ for $12 \mathrm{~h}$. Then $2 \mathrm{~mL}$ of the MGLE $(3.5 \%$ $\mathrm{w} / \mathrm{v}$ ) was added to the above suspension at $60^{\circ} \mathrm{C}$. After the reaction was completed and the Ag NPs formed, the color of mixture turned dark. Finally, the suspension of the Ag NPs/Mespilus germanica seed was centrifuged at $3500 \mathrm{rpm}$ for $15 \mathrm{~min}$. The prepared sediment was washed three times with deionized water and one time with ethanol and then dried overnight at room temperature.

\subsection{Photodegradation of methylene blue by Ag NPs/Mespilus germanica seed nanophotocatalyst (Ag NPs/MGS NPC)}

To evaluate the efficiency of the synthesized nanophotocatalyst, in a typical experiment, to $25 \mathrm{~mL}$ of an aqueous solution of methylene blue (MB, 5 ppm) 7 mg nanophotocatalyst (Ag NPs/MGS NPC), was added. Then the reaction container was placed in the dark for $30 \mathrm{~min}$ to achieve an adsorption/desorption equilibrium between Ag NPs/MGS NPC and dyes before irradiation. Then, this suspension was stirred under sunlight (10 AM). The UV-Vis spectrophotometer was used to investigate the progress of $M B$ photodegradation at certain time intervals. After the completion of the reaction, the catalyst was separated from the reaction mixture by brief centrifugation and washed with distilled water and ethanol and dried for the next run. The recycled catalyst was used 6 times without significant change in its activity, which confirms the stability and recyclability of the catalyst. The effects of factors such as $\mathrm{pH}$, temperature, light source and amount of nanophotocatalyst on the degradation of $\mathrm{MB}$ were also investigated and the percentage of degradation was measured according to the following equation

Degradation $\%=\frac{A_{0}-A}{A_{0}} \times 100$

In the above equation $A_{0}$ is the initial absorption of $M B$ before irradiation and $A$ is the absorption of $M B$ after irradiation at selected time intervals.

\section{Result and discussion}

Environmentally friendly syntheses of nanoparticles have been of interest in the past decade. Herein, we utilized a safe method for the synthesis of Ag NPs by using Mespilus germanica leaf extract (MGLE) as an inexpensive reducing and stabilizing agent. The synthesized NPs were immobilized on Mespilus germanica seed (MGS). The seed of this fruit is considered waste but here we succeed in using the Mespilus germanica seed as a support for Ag NPs as a new nanophotocatalyst (Scheme 1). 


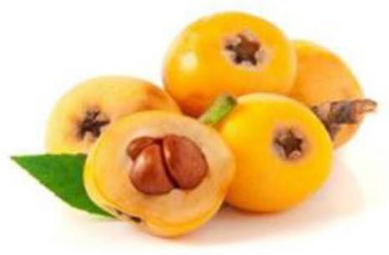

Mespilus germanica fruit

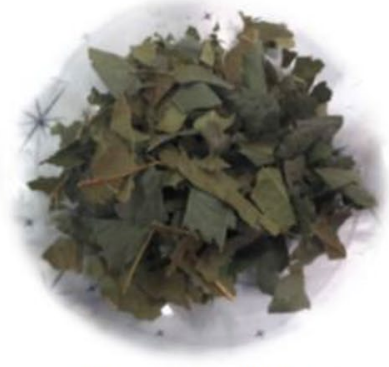

Mespilus germanica leaves

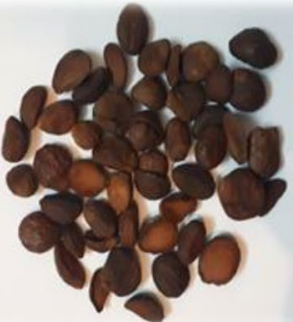

Mespilus germanica seed
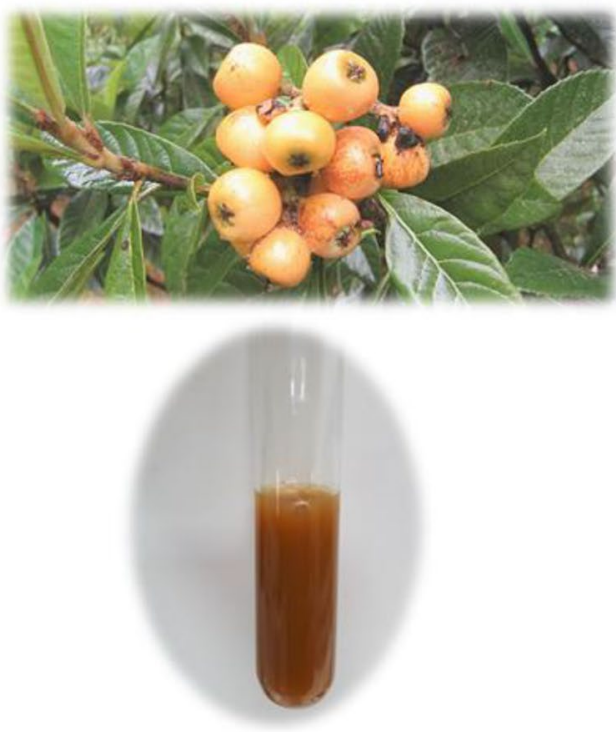

Mespilus germanica leaves extract

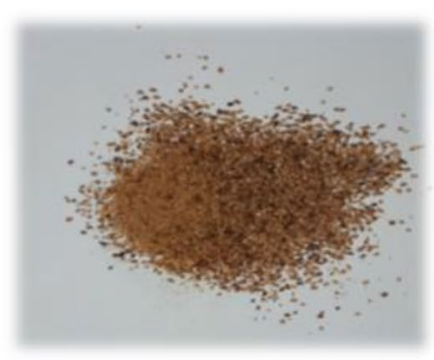

Mespilus germanica seed powder

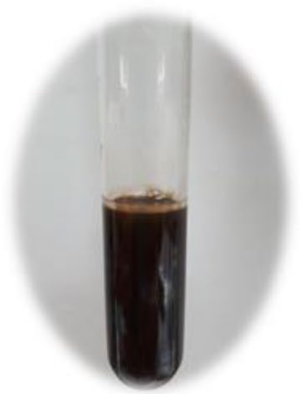

Biosynthesized Ag NPs with Mespilus germanica leaves extract

Scheme 1 Image of Ag NPs/Mespilus germanica seed nanophotocatalyst synthesis steps

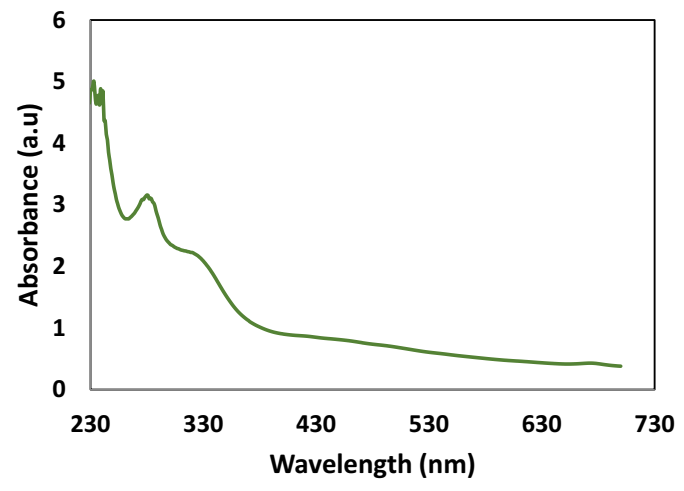

Fig. 1 UV-Vis spectra of MGLE

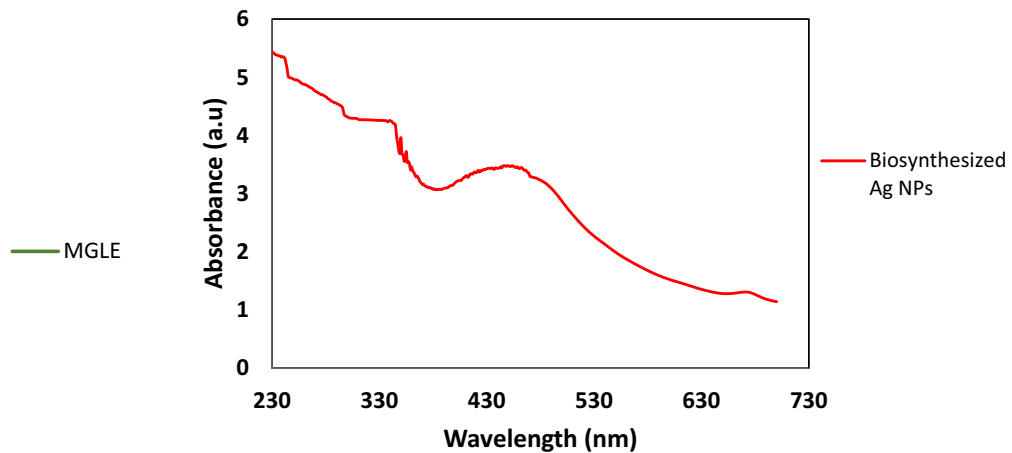

Fig. 2 UV-Vis spectra of biosynthesized Ag NPs 


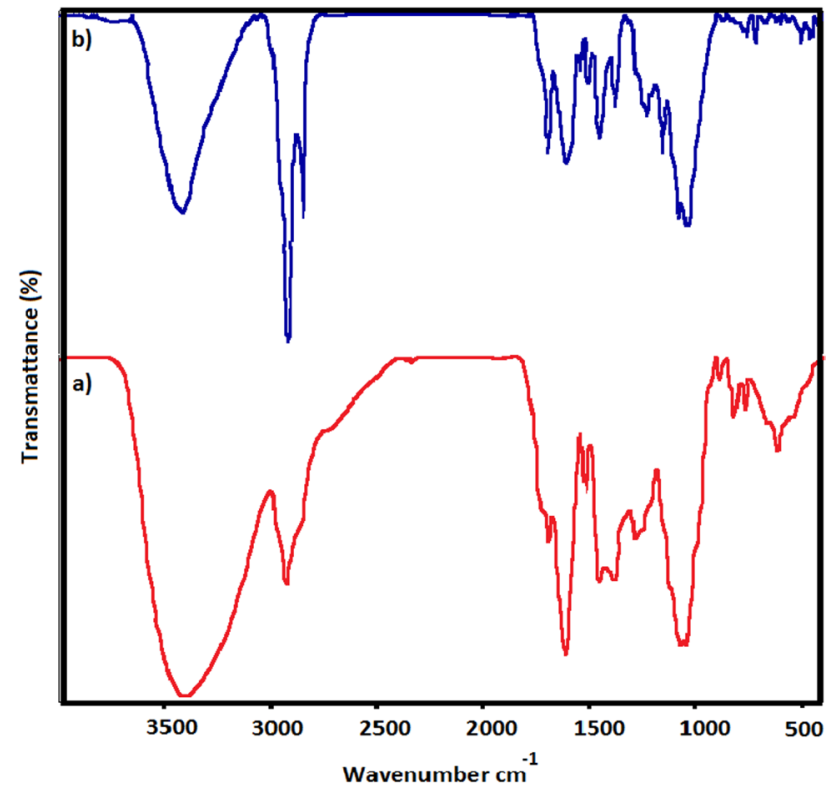

Fig. 3 FT-IR of MGLE (a) and biosynthesized Ag NPs (b)

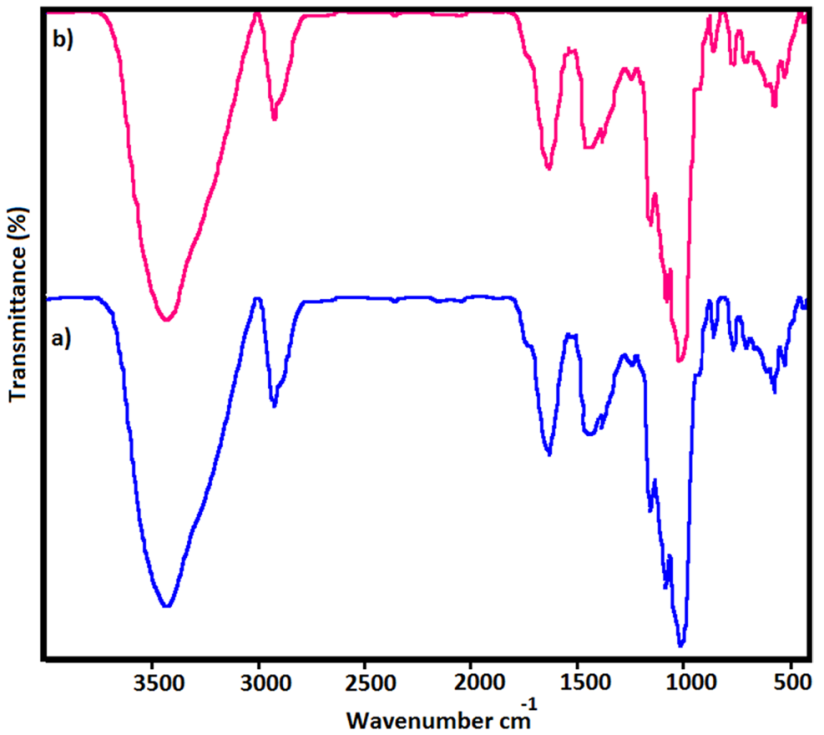

Fig. 4 FT-IR of MGS and Ag NPs/MGS NPC

\subsection{Characterization of MGLE and biosynthesized Ag NPs}

\subsubsection{UV-Vis of MGLE and biosynthesized of Ag NPS}

The UV-Vis spectra of MGLE and Ag NPs are shown in Figs. 1 and 2 respectively. The absorptions in the 200-300 $\mathrm{nm}$ range are related to the presence of polyphenolic compounds and conjugated aromatic systems containing benzoyl rings [52-54]. It is clear that after the

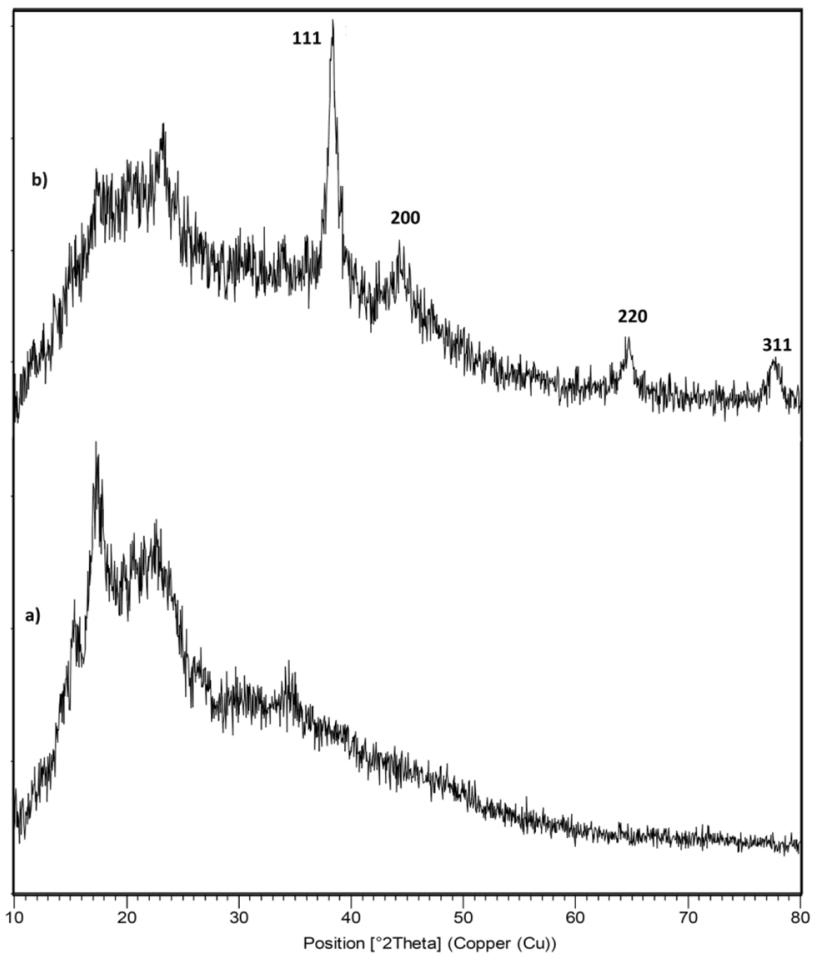

Fig. 5 XRD pattern of MGS (a) and Ag NPs/MGS NPC (b)

addition of MGLE to $\mathrm{Ag}^{1+}$ solution, the Ag NPs are formed (Fig. 2). This can be confirmed by the appearance of a peak in the $420-430 \mathrm{~nm}$ range. The stability of synthesized $\mathrm{Ag}$ NPs was studied using its UV-Vis spectrum after 30 days. The resulting UV-spectrum was similar to Fig. 2, which indicates good stability of Ag NPs as no significant changes in the shape and position of the absorption band were observed.

\subsubsection{FT-IR of MGLE and biosynthesized Ag NPs}

The FT-IR spectra of MGLE and biosynthesized Ag NPs are presented in Fig. 3, which shows only slight difference in the shape and location of absorption bands. As shown in Fig. $3 a$, the broad band at $3405 \mathrm{~cm}^{-1}$ relates to $\mathrm{OH}$ groups in compounds such as alcohols, phenols and carboxylic acids in the MGLE. Also absorption bands at 2927, 1681, 1618, 1518 and 1405, 1282, 1045, 889, 818, 766 and $610 \mathrm{~cm}^{-1}$ are related to $\mathrm{C}-\mathrm{H}$ stretching, $\mathrm{C}=\mathrm{O}$ stretching, $\mathrm{C}=\mathrm{C}$ stretching of aromatic ring, $\mathrm{C}-\mathrm{O}$ stretching of ether groups, $\mathrm{C}-\mathrm{H}$ bending of hydrocarbons and $\mathrm{O}-\mathrm{H}$ bending of hydroxyl groups, respectively. Figure $3 \mathrm{~b}$ displays feature due to several functional groups after formation of the desired Ag NPs by using MGLE. The presence of almost the same absorptions in the IR spectrum of Ag NPs as in MGLE indicates the existence of Ag NPs on the surface of MGLE. 

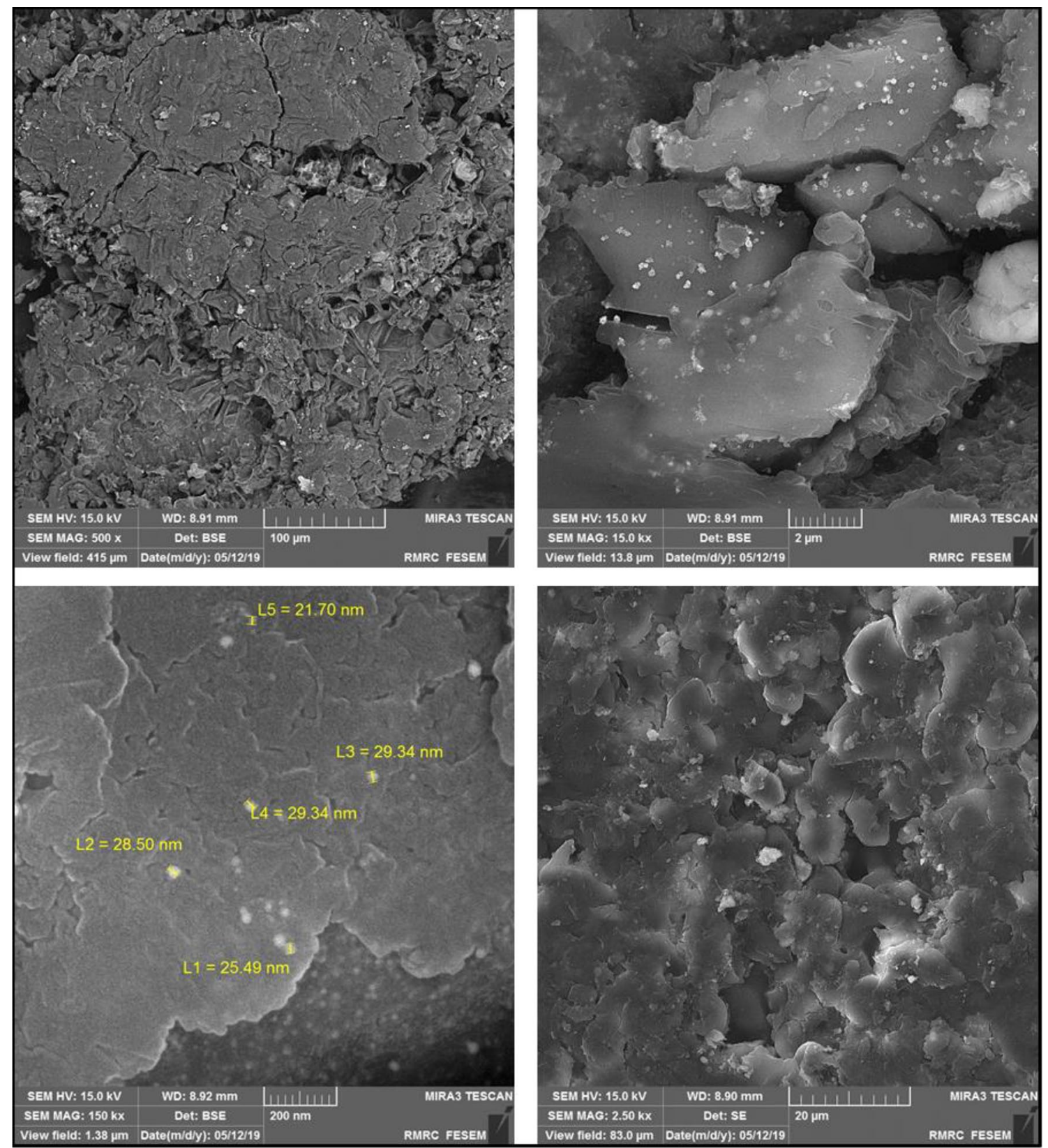

Fig. 6 FE-SEM of Ag NPs/MGS NPC

\subsection{Characterization of MGS and Ag NPs/MGS NPC}

\subsubsection{FT-IR of MGS and Ag NPs/MGS NPC}

IR spectroscopy was used to clarify the functional groups on the surface of the nanocatalyst. The FT-IR spectra of MGS and Ag NPs/MGS NPC were taken and shown in Fig. 4. As previously mentioned, the main component of Mespilus germanica seed is ascorbic acid. Therefore, the typical functional groups for this compound are expected to be observed in FT-IR spectra.
The IR spectrum which was shown in Fig. 4a indicates that the $\mathrm{O}-\mathrm{H}, \mathrm{C}-\mathrm{H}, \mathrm{C}=\mathrm{O}, \mathrm{C}=\mathrm{C}, \mathrm{C}-\mathrm{O}, \mathrm{C}-\mathrm{H}, \mathrm{O}-\mathrm{H}$ functional groups appeared at $3425,2925,1653,1521$ and 1436, $1155,1080,1019,859,763,576$ and $525 \mathrm{~cm}^{-1}$ respectively. Some of these functional groups play an important role in immobilization of Ag NPs on the surface of MGS. These absorptions are all shifted towards lower frequencies, which indicates a strong bond between the Ag NPs and MGS. In comparison with Mespilus germanica seeds, the FT-IR analysis of Ag NPs/MGS NPC confirms that there were no changes in the functional 
Fig. 7 EDS of Ag NPs/MGS NPC
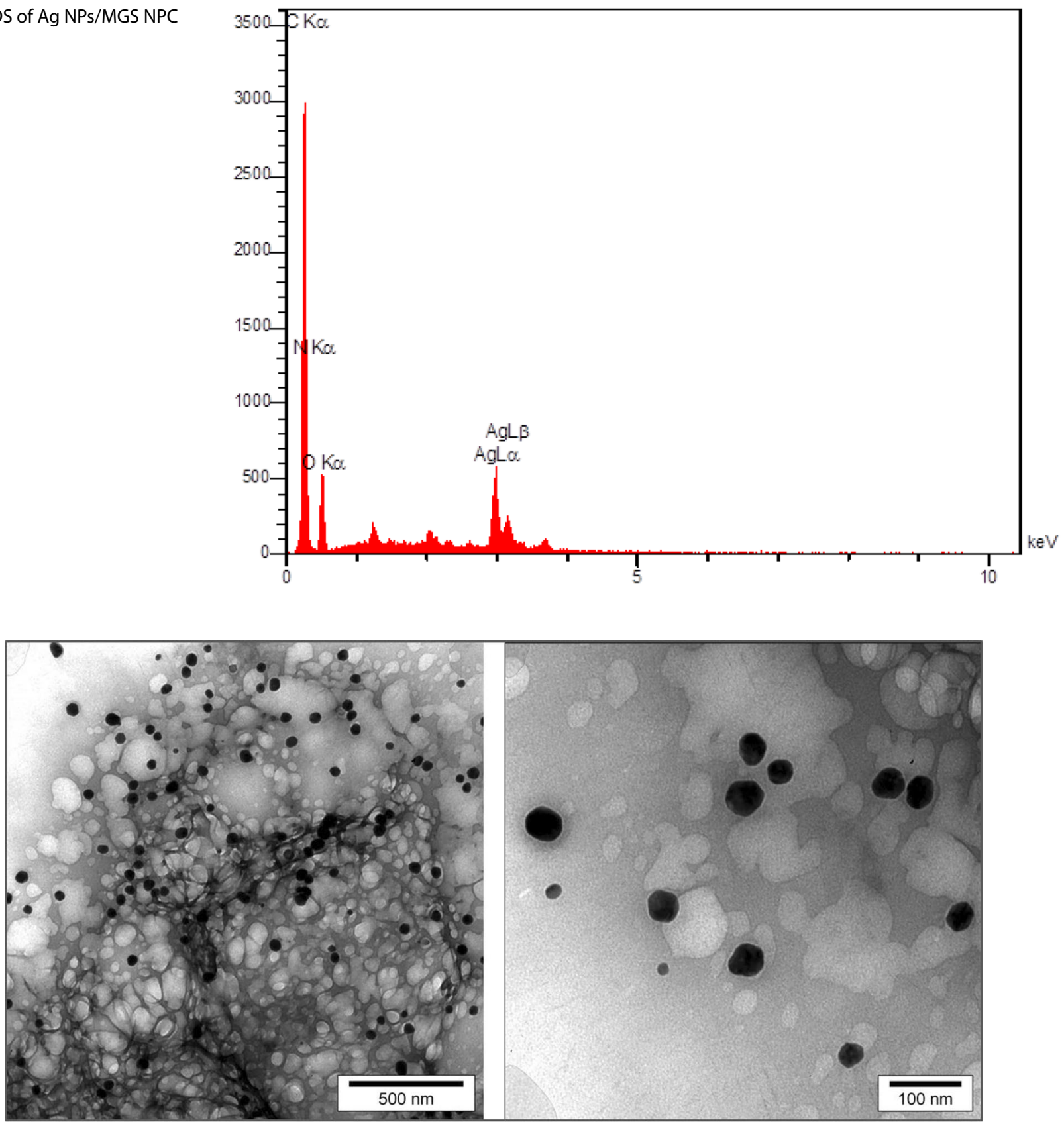

Fig. 8 TEM of Ag NPs/MGS NPC

groups after the immobilization of Ag NPs on the Mespilus germanica seeds.

\subsubsection{XRD of MGS and Ag NPs/MGS NPC}

In order to detect the phase of the samples and nanophotocatalyst components, the XRD patterns of MGS and Ag NPs/MGS NPC were obtained and are shown in Fig. 5. As shown in Fig. $5 \mathrm{a}$, there are three clear signals at $2 \theta$ of $16^{\circ}$, $22^{\circ}$ and $34^{\circ}$ which suggests the presence of ascorbic acid as the main component in MGS. This is consistent with the previous reports [55]. As shown in Fig. 5b, in addition to the peaks related to MGS, there are also peaks of silver nanoparticles. Figure $5 \mathrm{~b}$ clearly shows peaks at $38.2^{\circ}$, $44^{\circ}, 64^{\circ}$ and $78^{\circ}$ which corresponded to the crystal reflections of the (111), (200), (220) and (311) planes of Ag NPs, respectively. The results are consistent with the JCPDS card (87-0717) for Ag NPs [56]. Furthermore, the size of Ag NPs was calculated using the XRD results. The estimated 
Table 1 The influence of time on the photodegradation of MB dyes in the presence of $7.0 \mathrm{mg}$ of MGS and Ag NPS/MGS NPC

\begin{tabular}{lll}
\hline $\begin{array}{l}\text { Irradiation time (min) } \\
\text { sunlight }\end{array}$ & \multicolumn{2}{l}{ Percentage degradation (\%) } \\
\cline { 2 - 3 } & MGS (7.0 mg) & Ag NPS/MGS \\
& & NPC (7.0 mg) \\
\hline 0 & - & 0 \\
5 & - & 77 \\
10 & - & 83 \\
15 & - & 88 \\
20 & - & 90 \\
25 & - & 92 \\
30 & - & 93 \\
35 & - & 97 \\
35 & - & 97 \\
\hline
\end{tabular}

Reaction condition: $\mathrm{pH}=10, \mathrm{MB}$ concentration $=5 \mathrm{ppm}$

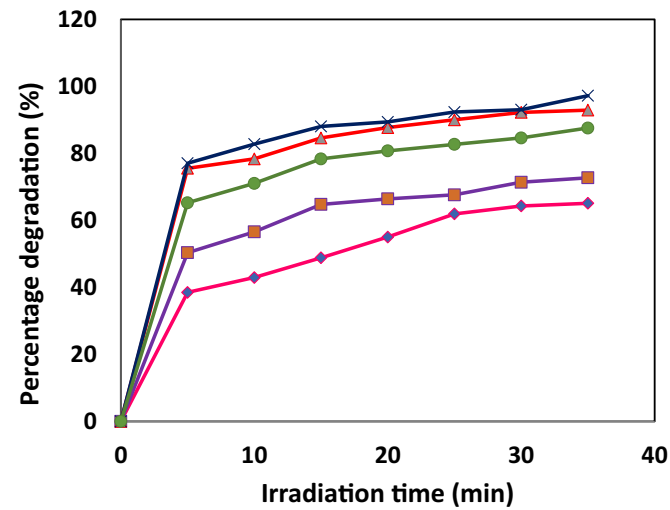

Fig. 9 The effect of $\mathrm{pH}$ on photodegradation of MB using Ag NPs/ MGS NPC

average size of Ag NPs is $21 \mathrm{~nm}$ using the Debye-Scherrer's equation. The results are consistent with TEM analysis.

\subsubsection{FE-SEM of Ag NPs/MGS NPC}

To evaluate the morphology of the prepared nanophotocatalyst, an analysis of the FE-SEM was performed and is shown in Fig. 6. The FE-SEM images of Ag NPs/MGS NPC indicate that the Ag NPs have spread over the porous surface MGS support and form smaller particles. The Ag NPs appear as bright points in Fig. 6 . It should be noted that the greater porosity in the structure of support increases the surface to volume ratio, which prevents the aggregation of nanoparticles and also increases photocatalytic activity.

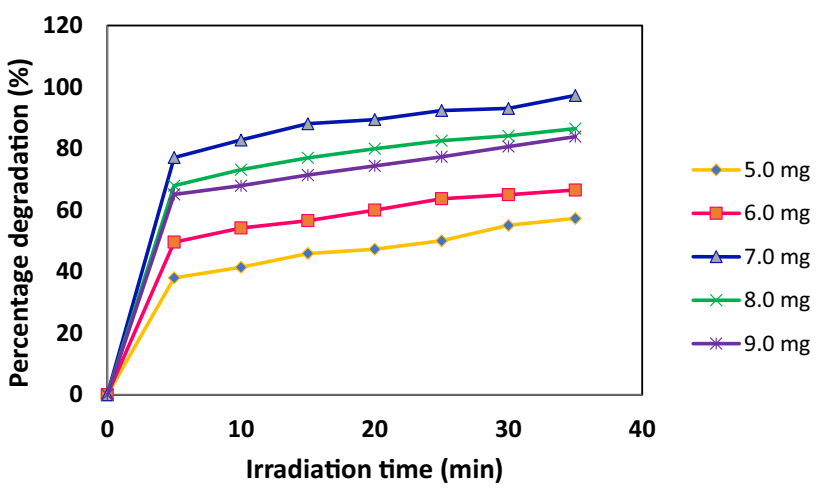

Fig. 10 The effect of the amount of Ag NPs/MGS NPC on the photodegradation of $\mathrm{MB}$

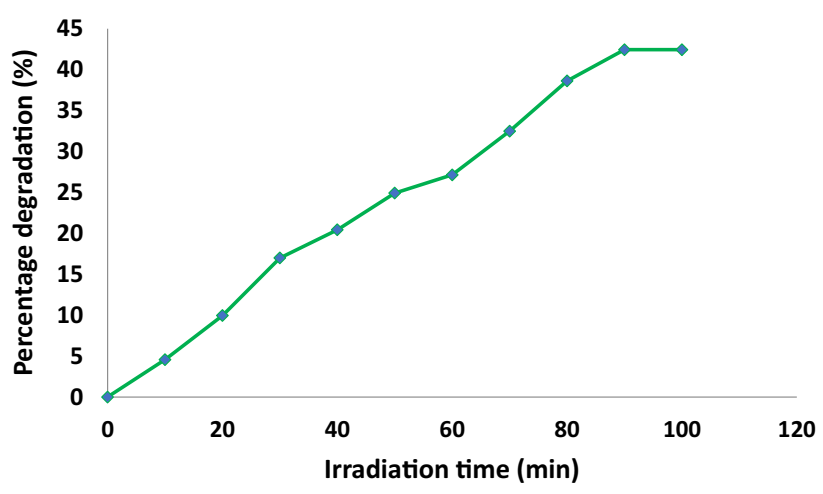

Fig. 11 The effect of light on the photodegradation of MB

\subsubsection{EDS of Ag NPs/MGS NPC}

EDS analysis was used to study the elemental composition of the Ag NPs/MGS NPC. The results are presented in Fig. 7. As shown in the Fig. 7, there are $\mathrm{C}, \mathrm{N}, \mathrm{O}$ and $\mathrm{Ag}$ elements in the nanophotocatalyst Ag NPs/MGS NPC. The presence of Ag in the nanophotocatalyst structure confirms the synthesis of Ag NPs on the MGS and these results are consistent with the above findings.

\subsubsection{TEM of Ag NPs/MGS NPC}

To illustrate the shape and size of the Ag NPs/MGS NPC, the TEM analysis was done and their images are exhibited in Fig. 8. These images show that MGS has porosity and the silver pseudo spherical nanoparticles with an average size of 10 to $30 \mathrm{~nm}$ are dispersed on the surface without any agglomeration. The Ag NPs are seen as dark dots on the MGS. 


\subsubsection{The photocatalytic activity of Ag NPs/MGS NPC}

The photocatalytic activity of Ag NPs/MGS NPC was studied by analysis of the degradation of methylene blue under sunlight in the presence of $7.0 \mathrm{mg}$ of the Ag NPs/MGS NPC. The reaction progressed in the presence of the nanophotocatalyst with $97 \%$ degradation in 35 min. Meanwhile, in the presence of $7.0 \mathrm{mg}$ of MGS support alone, no progress was observed. The results are presented in Table 1. Further, the effects of environmental factors on the photocatalytic activity were investigated.

\subsubsection{The effect of $\mathrm{pH}$ on photodegradation of MB}

Previous studies indicate that $\mathrm{pH}$ is the main factor in the photocatalytic degradation of dyes $[57,58]$. Therefore, the effect of $\mathrm{pH}$ (range 2-12) on the degradation of MB in the presence of $7.0 \mathrm{mg}$ of photocatalyst was evaluated under sunlight for $10 \mathrm{~min}$. The $\mathrm{pH}$ of the solution was adjusted by adding $1 \mathrm{M} \mathrm{HCl}$ and/or $\mathrm{NaOH}$. The results are shown in Fig. 9. These results reveal that by increasing the $\mathrm{pH}$ from

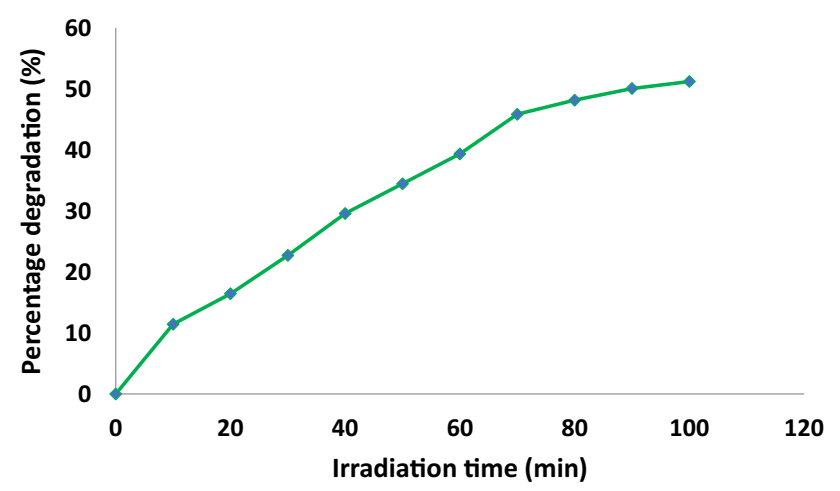

Fig. 12 The effect of temperature on photodegradation of MB (in the absence sunlight)
2 to 10 , the degradation of $\mathrm{MB}$ increases from 65 to $97 \%$. However, by increasing the $\mathrm{pH}$ from 10 to 12 , the degradation percentage of $\mathrm{MB}$ decreased to $88 \%$. Based on the results, it can be assumed that $\mathrm{pH}$ affects the properties of the nanophotocatalyst surface and the number of its active sites. Also, by increasing the $\mathrm{pH}$, the number of hydroxide ions in solution increases which can lead to generation of a higher radical concentration. Higher radical concentration will accelerate the dye degradation process. But at a pH higher than 10, high concentration of hydroxide ion may lead to degradation and change in the catalyst surface, and the photodegradation progress of the dye is reduced. Therefore $\mathrm{pH} 10$ was chosen as the optimum $\mathrm{pH}$.

\subsubsection{The effect of Ag NPs/MGS NPC amount on photodegradation of $\mathrm{MB}$}

In order to determine the importance of the amount of nanophotocatalyst on the rate of dye photodegradation, the degradation of $\mathrm{MB}$ aqueous solution (constant concentration of $5 \mathrm{ppm}$ ) was tested with different amounts of Ag NPs/MGS NPC (5.0-9.0 mg) at pH 10 under sunlight for times up to $35 \mathrm{~min}$. According to the results shown in Fig. 10, with an increase in the amount of photocatalyst from 5.0 to $7.0 \mathrm{mg}$, the degradation rate also increased from 57 to $97 \%$. The reason for this phenomenon is that the amount of catalyst effects the amount of light absorption [59]. By increasing the amount of photocatalyst from 7.0 to $9.0 \mathrm{mg}$, the dye degradation rate was reduced. Although we haven't investigate this effect any further, it may be due to the darkness of the solution and light scattering rather than light adsorption [60]. Therefore, the optimal amount of photocatalyst was $7.0 \mathrm{mg}$.

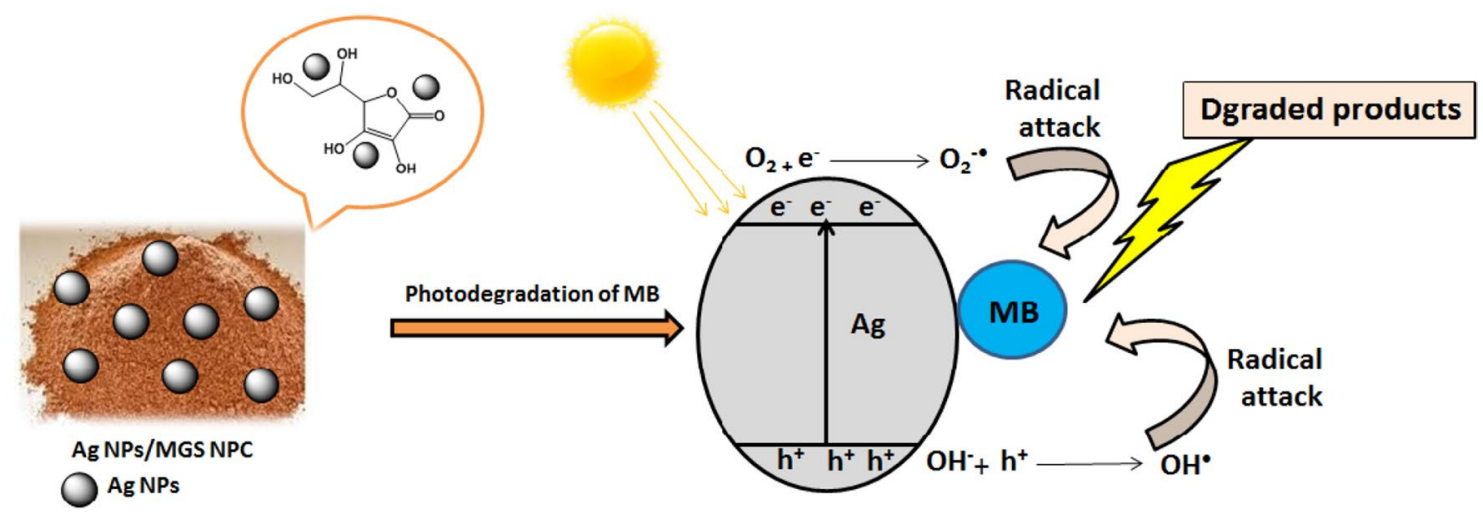

Fig. 13 The proposed mechanism for photodegradation of MB 
Table 2 Comparing the results of this work with other methods published in the literature for the degradation of $\mathrm{MB}$

\begin{tabular}{llllll}
\hline Entry & Photocatalyst & Light source & Time & $\begin{array}{l}\text { Degrada- } \\
\text { tion (\%) }\end{array}$ & References \\
\hline 1 & $\mathrm{Ag} \mathrm{NPs}$ & Solar light & $60 \mathrm{~min}$ & 1.1 & {$[65]$} \\
2 & $\mathrm{Ag} \mathrm{NPs}$ & Visible light & $12 \mathrm{~h}$ & 46 & {$[66]$} \\
3 & $\mathrm{Ag} \mathrm{NPs}$ & UV light & $4 \mathrm{~h}$ & 28 & {$[67]$} \\
4 & $\mathrm{Ag}-\mathrm{ZrO}{ }_{2}$ & Blue light & $60 \mathrm{~min}$ & 48 & {$[21]$} \\
5 & $\mathrm{Ag}-\mathrm{SiO}_{2}$ & Blue light & $60 \mathrm{~min}$ & 50 & {$[21]$} \\
6 & $\mathrm{Ag}-\mathrm{Zeolite}$ & Blue light & $60 \mathrm{~min}$ & 68 & {$[21]$} \\
7 & $\mathrm{Ag} / \mathrm{ZnO}$ nanoflower & Visible light & $2 \mathrm{~h}$ & 40 & {$[68]$} \\
8 & $\mathrm{Ag}-\mathrm{TiO}{ }_{2}$ & Visible light & $150 \mathrm{~min}$ & 50 & {$[69]$} \\
9 & $\mathrm{NiO}-\mathrm{ZnO}-\mathrm{Ag}$ nanocomposite & UV light & $90 \mathrm{~min}$ & 94 & {$[70]$} \\
10 & $\mathrm{Ag} \mathrm{NPs} / \mathrm{MGS} \mathrm{NPC}$ & Sunlight & $35 \mathrm{~min}$ & 97 & This work \\
\hline
\end{tabular}

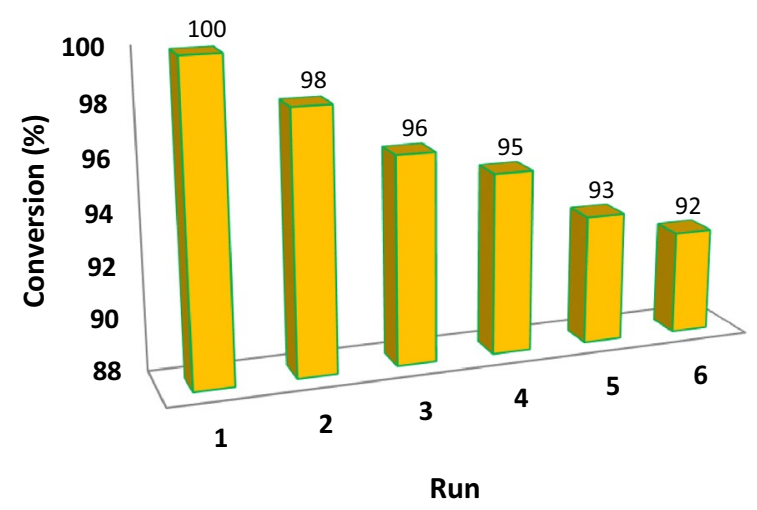

Fig. 14 Recycling of Ag NPs/MGS NPC on degradation of MB under similar conditions

\subsubsection{The effect of source light and temperature on photodegradation of $M B$}

The above-mentioned degradation reaction was repeated in the presence and absence of sunlight in order to investigate the effect of light on photocatalytic activity. As shown in Fig. 11, the degradation percentage of $M B$ in the absence of sunlight was $42 \%$ within 100 min but it was $97 \%$ in the presence of sunlight at ambient temperature within 35 min (Fig. 10). These results indicate the importance of sunlight as the source of photons. The reason for this observation can be attributed to an increase in radical creation which facilitates the process of photodegradation of the dyes [61]. Subsequently, the degradation reaction was carried out under the same conditions at $60^{\circ} \mathrm{C}$, but no significant change was observed in the progression of the reaction (Fig. 12). Therefore, sunlight was considered as a free, endless and safe source of photons for the photodegradation process of MB.

\subsection{Photocatalytic mechanism}

Herein, we propose a possible mechanism for the degradation of MB based on photoelectron-hole pairs. When the Ag NPs that are immobilized on the surface of Mespilus germanica seeds absorb sunlight, the surface electrons get excited and are transferred to a higher energy state. This is based on the Surface Plasmon Resonance (SPR) effect and the interband transition of the $4 \mathrm{~d}$ electrons to the $5 \mathrm{sp}$ band. Those electrons interact with water-soluble oxygen molecules to form superoxide anion radicals $\left(\mathrm{O}_{2}^{--}\right)$which degrade the MB molecules. On the other hand, the resulting holes in the valence band of silver react with water in a redox reaction to form hydroxyl radicals $\left(\mathrm{OH}^{\circ}\right)$. Finally, the radical species $\left(\mathrm{O}_{2}^{-\cdot}\right.$ and $\left.\mathrm{OH}^{-}\right)$will attack the $\mathrm{MB}$ molecules that are adsorbed onto the surface of catalyst and degrade the dye. In addition, methylene blue dye degradation by electron-hole pairs is also possible. Generally, the resulting electron-hole pair migrates onto the surface of the catalyst and will photodegrade the MB dye molecules [62-64]. The proposed mechanism is shown in Fig. 13.

Table 2 shows the comparison of the results of this protocol with the other reported method. The prepared nanophotocatalyst has shown excellent photocatalytic activity in the degradation of MB with the lowest time compared to the previously reported methods.

\subsection{Photocatalyst recyclability and reusability}

Recyclability and reusability are the two main factors for each nanophotocatalyst, especially for commercial and industrial applications. The silver nanophotocatalyst was separated by centrifugation after each reaction, washed 
with distilled water and ethanol, and then dried. They were used in the degradation reaction of MB under the same reaction conditions six times. The results are reported in the Fig. 14. As can be seen, the recycled nanophotocatalyst shows similar catalytic efficiency after several uses.

\section{Conclusion}

In this report, we have presented an inexpensive and green method for the synthesis of Ag NPs using Mespilus germanica leaf extract. Subsequently, the nanophotocatalyst was synthesized through immobilization of Ag NPs on the surface of Mespilus germanica seeds. The prepared nanophotocatalyst has shown excellent photocatalytic activity in the degradation of MB with the least amount of photocatalyst $(7.0 \mathrm{mg})$ under sunlight as a safe energy source. The catalyst can be used at least 6 times without significant decrease in its activity.

Acknowledgements The authors express appreciation to the Shahid Bahonar University of Kerman Faculty Research committee funds for its support of this research.

\section{Compliance with ethical standards}

Conflict of interest On behalf of all authors, the corresponding authors state that there is no conflict of interest.

\section{References}

1. Kubacka A, Fernandez-Garcia M, Colon G (2011) Advanced nanoarchitectures for solar photocatalytic applications. Chem Rev 112(3):1555-1614

2. Zhou W, Cao M, Li N, Su S, Zhao X, Wang J, Li X, Hu C (2013) Ag@ AgHPW as a plasmonic catalyst for visible-light photocatalytic degradation of environmentally harmful organic pollutants. Mater Res Bull 48(6):2308-2316

3. Lewis NS (2001) Light work with water. Nature 414(6864):589

4. Thompson TL, Yates JT (2006) Surface science studies of the photoactivation of $\mathrm{TiO}_{2}$ new photochemical processes. Chem Rev 106(10):4428-4453

5. Zhang M, Chen C, Ma W, Zhao J (2008) Visible-light-induced aerobic oxidation of alcohols in a coupled photocatalytic system of dye-sensitized $\mathrm{TiO}_{2}$ and TEMPO. Angew Chem Int Ed 47(50):9730-9733

6. Chen X, Mao SS (2007) Titanium dioxide nanomaterials: synthesis, properties, modifications, and applications. Chem Rev 107(7):2891-2959

7. Zou Z, Ye J, Sayama K, Arakawa H (2001) Direct splitting of water under visible light irradiation with an oxide semiconductor photocatalyst. Nature 414(6864):625

8. Ahmadi F, Rahimi-Nasrabadi M, Behpour M (2017) Synthesis $\mathrm{Nd}_{2} \mathrm{TiO}_{5}$ nanoparticles with different morphologies by novel approach and its photocatalyst application. J Mater Sci Mater Electron 28(2):1531-1536
9. Rahimi-Nasrabadi M, Pourmortazavi SM, Aghazadeh M, Ganjali MR, Karimi MS, Novrouzi P (2017) Optimizing the procedure for the synthesis of nanoscale gadolinium (III) tungstate as efficient photocatalyst. J Mater Sci Mater Electron 28(4):3780-3788

10. Eghbali-Arani $M$, Sobhani-Nasab A, Rahimi-Nasrabadi M, Pourmasoud S (2018) Green synthesis and characterization of $\mathrm{SmVO}_{4}$ nanoparticles in the presence of carbohydrates as capping agents with investigation of visible-light photocatalytic properties. J Electron Mater 47(7):3757-3769

11. Sobhani-Nasab A, Pourmasoud S, Ahmadi F, Wysokowski M, Jesionowski T, Ehrlich H, Rahimi-Nasrabadi M (2019) Synthesis and characterization of $\mathrm{MnWO}_{4} / \mathrm{TmVO}_{4}$ ternary nano-hybrids by an ultrasonic method for enhanced photocatalytic activity in the degradation of organic dyes. Mater Lett 238:159-162

12. Rahimi-Nasrabadi M, Ahmadi F, Eghbali-Arani M (2016) Simple morphology-controlled fabrication of $\mathrm{CdTiO}_{3}$ nanoparticles with the aid of different capping agents. J Mater Sci Mater Electron 27(12):13294-13299

13. Rahimi-Nasrabadi M, Pourmortazavi SM, Aghazadeh M, Ganjali MR, Karimi MS, Norouzi P (2017) Fabrication, characterization and photochemical activity of ytterbium carbonate and ytterbium oxide nanoparticles. J Mater Sci Mater Electron 28(13):9478-9488

14. Zhu M, Wang C, Meng D, Diao G (2013) In situ synthesis of silver nanostructures on magnetic $\mathrm{Fe}_{3} \mathrm{O}_{4} @ \mathrm{C}$ core-shell nanocomposites and their application in catalytic reduction reactions. $J$ Mater Chem A 1(6):2118-2125

15. Kumar A, Saxena D, Gupta MK (2013) Nanoparticle catalyzed reaction (NPCR): ZnO-NP catalyzed Ugi-reaction in aqueous medium. Green Chem 15(10):2699-2703

16. Rostami-Vartooni A, Alizadeh M, Bagherzadeh M (2015) Green synthesis, characterization and catalytic activity of natural bentonite-supported copper nanoparticles for the solvent-free synthesis of 1-substituted $1 \mathrm{H}-1,2,3$, 4-tetrazoles and reduction of 4-nitrophenol. Beilstein J Nanotechnol 6(1):2300-2309

17. Kamat PV (2002) Photophysical, photochemical and photocatalytic aspects of metal nanoparticles. ACS Publications, Washington

18. Kiran PP, Shivakiran Bhaktha B, Rao DN, De G (2004) Nonlinear optical properties and surface-plasmon enhanced optical limiting in $\mathrm{Ag}-\mathrm{Cu}$ nanoclusters co-doped in $\mathrm{SiO}_{2}$ sol-gel films. J Appl Phys 96(11):6717-6723

19. Voisin C, Del Fatti N, Christofilos D, Vallée F (2001) Ultrafast electron dynamics and optical nonlinearities in metal nanoparticles. ACS Publications, Washington

20. Zheng X, Xu W, Corredor C, Xu S, An J, Zhao B, Lombardi JR (2007) Laser-induced growth of monodisperse silver nanoparticles with tunable surface plasmon resonance properties and a wavelength self-limiting effect. J Phys Chem C 111(41):14962-14967

21. Chen X, Zheng Z, Ke X, Jaatinen E, Xie T, Wang D, Guo C, Zhao J, Zhu H (2010) Supported silver nanoparticles as photocatalysts under ultraviolet and visible light irradiation. Green Chem 12(3):414-419

22. Haritha E, Roopan SM, Madhavi G, Elango G, Arunachalam P (2017) Catunaregum spinosa capped Ag NPs and its photocatalytic application against amaranth toxic azo dye. J Mol Liq 225:531-535

23. Khan ZUH, Khan A, Shah A, Wan P, Chen Y, Khan GM, Khan AU, Tahir K, Muhammad N, Khan HU (2016) Enhanced photocatalytic and electrocatalytic applications of green synthesized silver nanoparticles. J Mol Liq 220:248-257

24. Paul B, Bhuyan B, Purkayastha DD, Dhar SS (2015) Green synthesis of silver nanoparticles using dried biomass of Diplazium 
esculentum (retz.) sw. and studies of their photocatalytic and anticoagulative activities. J Mol Liq 212:813-817

25. Wang L, Lu F, Liu Y, Wu Y, Wu Z (2018) Photocatalytic degradation of organic dyes and antimicrobial activity of silver nanoparticles fast synthesized by flavonoids fraction of Psidium guajava L. leaves. J Mol Liq 263:187-192

26. Essawy AA (2018) Silver imprinted zinc oxide nanoparticles: Green synthetic approach, characterization and efficient sunlight-induced photocatalytic water detoxification. J Clean Prod 183:1011-1020

27. Wu Y, Zhou Y, Xu H, Liu Q, Li Y, Zhang L, Liu H, Tu Z, Cheng X, Yang J (2018) Highly active, superstable, and biocompatible $\mathrm{Ag} /$ polydopamine/g- $\mathrm{C}_{3} \mathrm{~N}_{4}$ bactericidal photocatalyst: synthesis, characterization, and mechanism. ACS Sustain Chem Eng 6(11):14082-14094

28. Alshehri AH, Jakubowska M, Młożniak A, Horaczek M, Rudka D, Free C, Carey JD (2012) Enhanced electrical conductivity of silver nanoparticles for high frequency electronic applications. ACS Appl Mater Interfaces 4(12):7007-7010. https://doi.org/10.1021/ am3022569

29. Balantrapu K, Goia DV (2009) Silver nanoparticles for printable electronics and biological applications. J Mater Res 24(9):28282836. https://doi.org/10.1557/jmr.2009.0336

30. Nasrollahzadeh M, Sajadi SM, Hatamifard A (2016) Waste chicken eggshell as a natural valuable resource and environmentally benign support for biosynthesis of catalytically active $\mathrm{Cu} / \mathrm{egg}$ shell, $\mathrm{Fe}_{3} \mathrm{O}_{4}$ /eggshell and $\mathrm{Cu} / \mathrm{Fe}_{3} \mathrm{O}_{4}$ /eggshell nanocomposites. Appl Catal B 191:209-227

31. Sastry M, Ahmad A, Khan MI, Kumar R (2003) Biosynthesis of metal nanoparticles using fungi and actinomycete. Curr Sci 85(2):162-170

32. Lee S-W, Mao C, Flynn CE, Belcher AM (2002) Ordering of quantum dots using genetically engineered viruses. Science 296(5569):892-895

33. Awwad AM, Salem NM, Ibrahim QM, Abdeen AO (2015) Phytochemical fabrication and characterization of silver/silver chloride nanoparticles using Albizia julibrissin flowers extract. Adv Mater Lett 6(8):726-730

34. Virkutyte J, Varma RS (2011) Green synthesis of metal nanoparticles: biodegradable polymers and enzymes in stabilization and surface functionalization. Chem Sci 2(5):837-846

35. Kou J, Varma RS (2013) Expeditious organic-free assembly: morphologically controlled synthesis of iron oxides using microwaves. Nanoscale 5(18):8675-8679

36. Saxena A, Tripathi R, Zafar F, Singh P (2012) Green synthesis of silver nanoparticles using aqueous solution of Ficus benghalensis leaf extract and characterization of their antibacterial activity. Mater Lett 67(1):91-94

37. Shankar SS, Rai A, Ahmad A, Sastry M (2004) Rapid synthesis of $\mathrm{Au}, \mathrm{Ag}$, and bimetallic Au core-Ag shell nanoparticles using Neem (Azadirachta indica) leaf broth. J Colloid Interface Sci 275(2):496-502

38. Awwad AM, Salem NM (2012) Green synthesis of silver nanoparticles by mulberry leaves extract. Nanosci Nanotechnol 2(4):125-128

39. Kumar KP, Paul W, Sharma CP (2011) Green synthesis of gold nanoparticles with Zingiber officinale extract: characterization and blood compatibility. Process Biochem 46(10):2007-2013

40. Mittal AK, Chisti Y, Banerjee UC (2013) Synthesis of metallic nanoparticles using plant extracts. Biotechnol Adv 31(2):346-356

41. Nel $A E$, Mädler $L$, Velegol $D$, Xia $T$, Hoek EM, Somasundaran $P$, Klaessig F, Castranova V, Thompson M (2009) Understanding biophysicochemical interactions at the nano-bio interface. Nat Mater 8(7):543
42. Zhou Y, Yang Z-Y, Tang R-C (2018) Green and facile fabrication of AgNPs@ silk for colorful and multifunctional textiles using baicalin as a natural reductant. J Clean Production 170:940-949

43. Thakkar KN, Mhatre SS, Parikh RY (2010) Biological synthesis of metallic nanoparticles. Nanomed Nanotechnol Biol Med 6(2):257-262

44. Vinod V, Saravanan P, Sreedhar B, Devi DK, Sashidhar R (2011) A facile synthesis and characterization of Ag, Au and Pt nanoparticles using a natural hydrocolloid gum kondagogu (Cochlospermum gossypium). Colloids Surf B 83(2):291-298

45. Wang M, Tian D, Tian P, Yuan L (2013) Synthesis of micron-SiO $@$ nano-Ag particles and their catalytic performance in 4-nitrophenol reduction. Appl Surf Sci 283:389-395

46. Veličković MM, Radivojević DD, Oparnica ČĐ, Nikićević NJ, Živković M, Đorđević NO, Vajs V, Tešević V (2013) Volatile compounds in Medlar fruit (Mespilus germanica L.) at two ripening stages. Hem ind 67(3):437-441

47. Kalyoncu IH, Ersoy N, Elidemir AY, Tolay I (2013) Some physicochemical and nutritional properties of 'Musmula' Medlar (Mespilus germanica L.) grown in northeast Anatolia. In: Proceedings of world academy of science, engineering and technology, vol 78. World Academy of Science, Engineering and Technology (WASET), p 1380

48. Ghorbani A (2005) Studies on pharmaceutical ethnobotany in the region of Turkmen Sahra, north of Iran:(part 1): general results. J Ethnopharmacol 102(1):58-68

49. Bibalani GH, Mosazadeh-Sayadmahaleh F (2012) Medicinal benefits and usage of medlar (Mespilus germanica) in Gilan Province (Roudsar District). Iran J Med Plants Res 6(7):1155-1159

50. Nabavi SF, Nabavi SM, Ebrahimzadeh MA, Asgarirad H (2011) The antioxidant activity of wild medlar (Mespilus germanica L.) fruit, stem bark and leaf. Afr J Biotechnol 10(2):283-289

51. Rashidi M, Islami MR, Tikdari AM (2019) Green synthesis of Pd nanoparticles supported on modified Nonpareil almond shell using almond hull extract: a beneficial nanocatalyst for convenient reduction of organic dyes. J Mater Sci Mater Electron 30:18111-18122

52. Dai R, Chen J, Lin J, Xiao S, Chen S, Deng Y (2009) Reduction of nitro phenols using nitroreductase from $E$. coli in the presence of NADH. J Hazard Mater 170(1):141-143

53. Naik B, Hazra S, Muktesh P, Prasad VS, Ghosh NN (2011) A facile method for preparation of Ag nanoparticle loaded MCM-41 and study of its catalytic activity for reduction of 4-nitrophenol. Sci Adv Mater 3(6):1025-1030

54. Rostami-Vartooni A, Nasrollahzadeh M, Alizadeh M (2016) Green synthesis of seashell supported silver nanoparticles using Bunium persicum seeds extract: application of the particles for catalytic reduction of organic dyes. J Colloid Interface Sci 470:268-275

55. Palma-Rodríguez HM, Alvarez-Ramírez J, Vargas-Torres A (2018) Using modified starch/maltodextrin microparticles for enhancing the shelf life of ascorbic acid by the spray-drying method. Starch-Stärke 70(7-8):1700323

56. Veisi H, Azizi S, Mohammadi P (2018) Green synthesis of the silver nanoparticles mediated by Thymbra spicata extract and its application as a heterogeneous and recyclable nanocatalyst for catalytic reduction of a variety of dyes in water. J Clean Prod 170:1536-1543

57. Sakthivel S, Neppolian B, Shankar M, Arabindoo B, Palanichamy M, Murugesan V (2003) Solar photocatalytic degradation of azo dye: comparison of photocatalytic efficiency of $\mathrm{ZnO}$ and $\mathrm{TiO}_{2}$. Sol Energy Mater Sol Cells 77(1):65-82

58. Wang $Y$ (2000) Solar photocatalytic degradation of eight commercial dyes in $\mathrm{TiO}_{2}$ suspension. Water Res 34(3):990-994 
59. Nam W, Kim J, Han G (2002) Photocatalytic oxidation of methyl orange in a three-phase fluidized bed reactor. Chemosphere 47(9):1019-1024

60. Gao B, Ma Y, Cao Y, Yang W, Yao J (2006) Great enhancement of photocatalytic activity of nitrogen-doped titania by coupling with tungsten oxide. J Phys Chem B 110(29):14391-14397

61. Hussin F, Lintang HO, Lee SL, Yuliati L (2017) Photocatalytic synthesis of reduced graphene oxide-zinc oxide: effects of light intensity and exposure time. J Photochem Photobiol A 340:128-135

62. Park H, Hira SA, Muthuchamy N, Park S, Park KH (2019) Synthesis of silver nanostructures in ionic liquid media and their application to photodegradation of methyl orange. Nanomater Nanotechnol 9:1847980419836500. https://doi.org/10.1177/18479 80419836500

63. Khan AU, Yuan Q, Khan ZUH, Ahmad A, Khan FU, Tahir K, Shakeel M, Ullah S (2018) An eco-benign synthesis of AgNPs using aqueous extract of Longan fruit peel: antiproliferative response against human breast cancer cell line MCF-7, antioxidant and photocatalytic deprivation of methylene blue. J Photochem Photobiol B 183:367-373. https://doi.org/10.1016/j.jphotobiol .2018.05.007

64. Singh J, Dhaliwal AS (2018) Plasmon-induced photocatalytic degradation of methylene blue dye using biosynthesized silver nanoparticles as photocatalyst. Environ Technol. https://doi. org/10.1080/09593330.2018.1540663

65. Vanaja M, Paulkumar K, Baburaja M, Rajeshkuma RS, Gnanajobitha G, Malarkodi C, Sivakavinesan M, Annadurai G (2014) Degradation of methylene blue using biologically synthesized silver nanoparticles. Bioinorg Chem Appl. https://doi. org/10.1155/2014/742346
66. Singh T, Jyoti K, Patnaik A, Chauhan R, Kumar N (2016) Application of silver nanoparticles synthesized from Raphanus sativus for catalytic degradation of organic dyes. MATEC Web Conf 57:05003

67. Hiragond CB, Kshirsagar AS, Khanna DP (2018) Electro-photocatalytic degradation of methylene blue dye using various nanoparticles: a demonstration for undergraduates. J Nanomed Res 7(4):254-257

68. Fageria P, Gangopadhyay S, Pande S (2014) Synthesis of ZnO/Au and $\mathrm{ZnO} / \mathrm{Ag}$ nanoparticles and their photocatalytic application using UV and visible light. RSC Adv 4(48):24962-24972. https:// doi.org/10.1039/C4RA03158J

69. Dong P, Yang F, Cheng X, Huang Z, Nie X, Xiao Y, Zhang X (2019) Plasmon enhanced photocatalytic and antimicrobial activities of $\mathrm{Ag}-\mathrm{TiO}_{2}$ nanocomposites under visible light irradiation prepared by DBD cold plasma treatment. Mater Sci Eng C 96:197204. https://doi.org/10.1016/j.msec.2018.11.005

70. Aydoghmish SM, Hassanzadeh-Tabrizi SA, Saffar-Teluri A (2019) Facile synthesis and investigation of $\mathrm{NiO}-\mathrm{ZnO}-\mathrm{Ag}$ nanocomposites as efficient photocatalysts for degradation of methylene blue dye. Ceram Int 45(12):14934-14942. https://doi. org/10.1016/j.ceramint.2019.04.229

Publisher's Note Springer Nature remains neutral with regard to jurisdictional claims in published maps and institutional affiliations. 